\title{
First Trimester Hemolysis, Elevated Liver Enzymes, Low Platelets Syndrome in a Surrogate Pregnancy
}

\author{
Emily Myer, MD ${ }^{1}$ James Hill, MD ${ }^{1}$ \\ ${ }^{1}$ Department of Obstetrics and Gynecology and Section of Maternal- \\ Fetal Medicine, Eastern Virginia Medical School, Norfolk, Virginia \\ Am J Perinatol Rep 2015;5:e212-e214.
}

Address for correspondence James Hill, MD, Department of Obstetrics and Gynecology, Eastern Virginia Medical School, 825 Fairfax Avenue, Suite 544, Norfolk, VA 23507 (e-mail: hilljb@evms.edu).

\begin{abstract}
Keywords

- HELLP syndrome

- previable

- preeclampsia

- gestational surrogate

- in vitro fertilization
\end{abstract}

Background The occurrence of hemolysis, elevated liver enzymes, low platelets (HELLP) syndrome before 20 weeks of gestation is rare. HELLP is a possible but rare syndrome in gestational surrogate pregnancies for surrogates with risk factors for development of preeclampsia.

Case A 32-year-old patient with chronic hypertension and positive antinuclear antibody presented for prenatal care at 13 weeks and 1 day. She was a surrogate for the embryo of a 43-year-old couple. By 15 weeks she developed uncontrolled hypertension requiring hospitalization. She was expectantly managed until her condition deteriorated. At 16 weeks and 1 day she developed hemolysis, elevated liver enzymes, thrombocytopenia, and fetal demise.

Conclusions HELLP syndrome is rare and carries a significant morbidity and mortality for the mother and fetus. Clinicians should encourage the surrogate to share her medical history with the embryo donor for appropriate counseling on pregnancy risks.
Hypertensive disorders of pregnancy complicate up to $10 \%$ of pregnancies and are one of the leading causes of maternal and perinatal morbidity and mortality. ${ }^{1}$ By definition, preeclampsia is the development of blood pressure elevation after 20 weeks of gestation. The occurrence of hemolysis, elevated liver enzymes, low platelets (HELLP) syndrome before 20 weeks of gestation is extremely rare but has been reported. $^{2-6}$ Some studies suggest there is an increased risk for preeclampsia with in vitro fertilization. ${ }^{7}$ We present the first case of HELLP syndrome in a gestational surrogate at 16 weeks gestation.

\section{Case}

A 32-year-old African American G3P2002 presented for prenatal care at 13 weeks and 1 day gestation. She is a gestational surrogate for the embryo of a 43-year-old couple who is a work-colleague and friend. Her medical history is complicat-

received

June 16, 2015 accepted after revision

June 29, 2015

published online

September 7, 2015
$10.1055 / \mathrm{s}-0035-1563389$ ISSN 2157-7005. ed by chronic hypertension controlled on methyldopa, asthma, and the history of antinuclear antibody (ANA)-positive status. Her pregnancy history is complicated by two prior cesarean deliveries, and she is a gestational surrogate, with a history of an early demise of one twin embryo at 9 weeks gestation. She was initially started on vaginal and intramuscular progesterone during the early part of her pregnancy, and continued on a low-dose aspirin throughout her pregnancy. At her initial appointment her blood pressure (BP) was in the severe range at $168 / 97 \mathrm{~mm} \mathrm{Hg}$ and her urine analysis showed no protein. Her BP medication was increased, a 24hour urine total protein was ordered in addition to baseline laboratories. Her 24-hour urine protein was normal at 160 $\mathrm{mg} / 24 \mathrm{~h}$ and her platelet count was noted to be $96,000 / \mu \mathrm{L}$. At her follow-up visit, she again had severe range BP of 165/ $82 \mathrm{~mm} \mathrm{Hg}$ and her urine protein dipstick was $4+$. She was sent to labor and delivery for evaluation. She was admitted for 4 days, her 24-hour urine protein worsened to $1.1 \mathrm{~g}$ and her

Copyright $\odot 2015$ by Thieme Medical Publishers, Inc., 333 Seventh Avenue, New York, NY 10001, USA. Tel: +1(212) 584-4662.

\section{License terms}

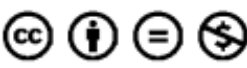


platelets were stable at 85,000 to $109,000 / \mu \mathrm{L}$. Rheumatology was consulted given her history of ANA speckled positive status (low titer of 1:40) and additional laboratories, including complement levels, anticardiolipin, $\beta$-2-glycoprotein, antihistone, anticitrulline, antidouble-stranded DNA, rheumatoid factor were drawn and were normal. Rheumatology had no further recommendations. She had an echocardiogram that was also normal. Her blood pressure normalized with additional medication. She remained asymptomatic and was discharged for expectant management at 15 weeks and 4 days. At 16 weeks and 1 day, she presented for follow-up to the clinic and fetal demise was noted on ultrasound. Her BP was noted to be in the severe range at $180 / 104 \mathrm{~mm} \mathrm{Hg}$. She was sent to labor and delivery for labor induction. At this time, her preeclampsia laboratories were grossly abnormal, consistent with HELLP syndrome with platelets of $60,000 / \mu \mathrm{L}$, aspartate aminotransferase $147 \mathrm{IU} / \mathrm{L}$, alanine aminotransferase $154 \mathrm{IU} / \mathrm{L}$, uric acid $6.4 \mathrm{mg} / \mathrm{dL}$, lactate dehydrogenase 493 $\mathrm{IU} / \mathrm{L}$. She was started on magnesium for seizure prophylaxis and received misoprostol for labor induction. She had a successful vaginal delivery and required curettage for retained placenta. She was kept on magnesium for an additional 24 hours after delivery and by her 2 week follow-up visit, all laboratory values had normalized and her blood pressure was well controlled with low-dose labetalol.

A full autopsy was performed. Pathology of the fetus A revealed small growth age at $50 \%$ of expected weight $(51 \mathrm{~g})$ but no anatomic or microscopic abnormality. Fetus B was consistent with early fetal demise and no abnormalities were noted. Placenta A had patchy villous edema, accelerated villous maturation, deciduitis, three-vessel cord, and small placenta. Placenta B had extensive necrosis and decidual vasculopathy.

\section{Comments}

This is a unique case of early-onset HELLP syndrome. Assisted reproduction has been shown to have an increased risk of preeclampsia in some studies ${ }^{7,8}$ but not others. ${ }^{9}$ Part of the risk may be inherent to maternal advanced age, medical comorbidities, and an increased risk of multiple gestation. ${ }^{10}$ While gestational surrogates have been used for embryo donors with a poor obstetric history ${ }^{8}$; our case is a unique case in which a patient at increased risk for preeclampsia based on a positive ANA and chronic hypertension was chosen as the gestational surrogate. The American Society of Reproductive Medicine has an ethical guideline entitled "Consideration of the gestational carrier: a committee opinion." Though it mentions that financial payments may create incentives that might encourage potential gestational carriers to lie about heath conditions or family history, there is no recommendation for sharing of medical history with the donor family. The only two considerations for becoming a gestational carrier are that of being greater than 21-years-old and having at least one prior successful delivery. ${ }^{11,12}$

The incidence of HELLP is 5 to 76 per 10,000 deliveries. ${ }^{13}$ In most cases diagnosed antenatally (65\%) at a median gestation of 36 weeks (range, 25-41 weeks). ${ }^{14}$ Risk factors are nulliparity, history of gestational hypertensive disorder in prior gestation, chronic hypertension in nulliparous women, autoimmune disease, renal disease, multiple pregnancies. ${ }^{14}$ The perinatal mortality rate is 15 per 1,000 total births. ${ }^{14}$ Maternal morbidity includes coagulopathy, transfusion, intensive care unit admission, eclampsia, pulmonary edema, sepsis, liver hematoma, hepatic encephalopathy, renal failure, subarachnoid hemorrhage, delivery by cesarean, ${ }^{14}$ and maternal mortality is $1 \% .{ }^{15}$ Due to the high risks of HELLP syndrome, we recommend careful selection of low-risk gestational surrogates to optimize pregnancy outcomes.

Note

There was no funding received for conducting this project.

\section{References}

1 American College of Obstetricians and Gynecologists; Task Force on Hypertension in Pregnancy. Hypertension in pregnancy. Report of the American College of Obstetricians and Gynecologists' Task Force on Hypertension in Pregnancy. Obstet Gynecol 2013;122(5): 1122-1131

2 Bornstein E, Barnhard Y, Atkin R, Divon MY. HELLP syndrome: a rare, early presentation at 17 weeks of gestation. Obstet Gynecol 2007;110(2 Pt 2):525-527

3 Sherer DM, Dalloul M, Stimphil R, et al. Acute onset of severe hemolysis, elevated liver enzymes, and low platelet count syndrome in a patient with a partial hydatidiform mole at 17 weeks gestation. Am J Perinatol 2006;23(3):163-166

4 Stefos T, Plachouras N, Mari G, Cosmi E, Lolis D. A case of partial mole and atypical type I triploidy associated with severe HELLP syndrome at 18 weeks' gestation. Ultrasound Obstet Gynecol 2002;20(4):403-404

5 Haram K, Trovik J, Sandset PM, Hordnes K. Severe syndrome of hemolysis, elevated liver enzymes and low platelets (HELLP) in the 18th week of pregnancy associated with the antiphospholipidantibody syndrome. Acta Obstet Gynecol Scand 2003;82(7): 679-680

6 McMahon LP, Smith J. The HELLP syndrome at 16 weeks gestation: possible association with the antiphospholipid syndrome. Aust NZ J Obstet Gynaecol 1997;37(3):313-314

7 Shanis L, Jessmon P, Sinaii N, Armant DN, Stratton P. IVF and increased risk for preeclampsia revisited: a meta-analysis. Fertil Steril 2011;96(3):S181

8 Calhoun KC, Barnhart KT, Elovitz MA, Srinivas SK. Evaluating the Association between Assisted Conception and the Severity of Preeclampsia. ISRN Obstet Gynecol 2011;2011; 928592

9 Marchand E, Poncelet C, Carbillon L, Pharisien I, Tigaizin A, Chanelles $\mathrm{O}$. Is there more complications with pregnancies from the assisted reproductive technology than spontaneous pregnancies? A retrospective study over 6 years [in French]. J Gynecol Obstet Biol Reprod (Paris) 2011;40(6):522-528

10 Silberstein T, Levy A, Harlev A, Saphier O, Sheiner E. Perinatal outcome of pregnancies following in vitro fertilization and ovulation induction. J Matern Fetal Neonatal Med 2014;27(13): 1316-1319

11 Farley DM, Grainger DA, Tjaden BL, Frazier LM, Maki JE. Use of a gestational carrier for a patient with recurrent adverse pregnancy outcomes from early onset severe pre-eclampsia. Fertil Steril 2007;87(1):189.e1-189.e3 
12 Ethics Committee of the American Society for Reproductive Medicine. Consideration of the gestational carrier: a committee opinion. Fertil Steril 2013;99(7):1838-1841

13 Martin JN Jr, Rinehart BK, May WL, Magann EF, Terrone DA, Blake PG. The spectrum of severe preeclampsia: comparative analysis by HELLP (hemolysis, elevated liver enzyme levels, and low platelet count) syndrome classification. Am J Obstet Gynecol 1999;180(6 Pt 1):1373-1384
14 Fitzpatrick KE, Hinshaw K, Kurinczuk JJ, Knight M. Risk factors, management, and outcomes of hemolysis, elevated liver enzymes, and low platelets syndrome and elevated liver enzymes, low platelets syndrome. Obstet Gynecol 2014;123(3): 618-627

15 Sibai BM. Diagnosis, controversies, and management of the syndrome of hemolysis, elevated liver enzymes, and low platelet count. Obstet Gynecol 2004;103(5 Pt 1):981-991 